NASA Technical Memorandum 106492

AIAA-94-0365

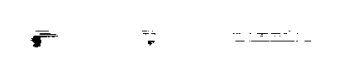

\title{
Improving Diffusing S-Duct Performance by Secondary Flow Control
}

Bruce A. Reichert and Bruce J. Wendt

Lewis Research Center

Cleveland, Ohio

$$
\begin{aligned}
& \text { (NASA-TM-106492) IMPROVING } \\
& \text { DIFFUSING S-DUCT PERFORMANCE BY } \\
& \text { SECONDARY FLOW CONTROL (NASA) } \\
& 12 \mathrm{P}
\end{aligned}
$$

N94-25182

Unclas

G3/02 0207537

Prepared for the

32nd Aerospace Sciences Meeting and Exhibit sponsored by the American Institute of Aeronautics and Astronautics Reno, Nevada, January 10-13, 1994 
$\pm=\ldots+\cdots$

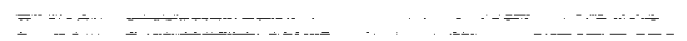

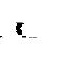

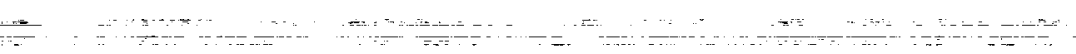

$\cdots$

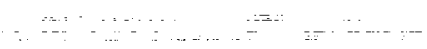




\title{
Improving Diffusing S-Duct Performance by Secondary Flow Control
}

\author{
Bruce A. Reichert* and Bruce J. Wendt ${ }^{\dagger}$ \\ National Aeronautics and Space Administration \\ Lewis Research Center \\ Cleveland, Ohio 44135
}

\begin{abstract}
The objective of this research was to study ways to reduce inlet flow distortion (i.e., total pressure nonuniformity) and improve total pressure recovery in a diffusing S-duct. This was accomplished by controlling the development of secondary flows within the duct through the use of tapered-fin type vortex generators. Reported herein are results for the bare duct and seven different configurations of vortex generators. Data presented for each configuration include surface static pressure, surface flow visualization, and exit plane total pressure and transverse velocity. The performance of each configuration was assessed by calculating total pressure recovery and inlet distortion descriptors from the data and comparing them to the values for the bare duct. The best configuration tested reduced distortion (as measured by the $\mathrm{DC}(45)$ and DC(90) descriptors) by more than $50 \%$ while improving total pressure recovery by $0.5 \%$. These results should provide valuable guidance in designing vortex generator installations in ducts and for assessing the accuracy of CFD methods to calculate duct flows with installed vortex generators.
\end{abstract}

Nomenclature

$\begin{array}{lll}A_{1} & = & \text { duct inlet area } \\ A_{2} & = & \text { duct exit area } \\ c & = & \text { vortex generator length, Fig. 3 } \\ C p & = & \text { static pressure coefficient, Eq. } 2 \\ C p_{0} & = & \text { total pressure coefficient, Eq. } 3 \\ D & = & \text { S-duct duct diameter, Eq. } 1 \\ D_{1} & = & \text { S-duct inlet duct diameter } \\ D_{2} & = & \text { S-duct exit duct diameter } \\ D C(\theta) & = & \text { distortion descriptor, Eq. } 4 \\ h & = & \text { vortex generator height, Fig. } 3 \\ l & = & \text { vortex generator lateral spacing, } \\ M & & \text { Fig. } 4 \\ 0 & = & \text { Mach number } \\ & = & \text { vortex generator lateral offset, } \\ p & & \text { Fig. } 3 \\ & & \text { static pressure }\end{array}$

-Aerospace Engineer, Inlet, Duct, and Nozzle Flow Physics Branch, Member AIAA:

${ }^{\dagger}$ Aerospace Engineer, National Research Council Associate, Member AIAA.

\begin{tabular}{|c|c|c|}
\hline pref & $=$ & $\begin{array}{l}\text { static pressure at } s / D_{1}=-0.5 \\
\text { and } r=D_{1} / 2\end{array}$ \\
\hline$p_{0}$ & $=$ & total pressure \\
\hline$\overline{p_{0}}$ & $=$ & average total pressure \\
\hline$p_{0, \text { ref }}$ & $=$ & $\begin{array}{l}\text { total pressure at } s / D_{1}=-0.5 \\
\text { and } r=0\end{array}$ \\
\hline $\bar{q}$ & $=$ & $\begin{array}{l}\text { average dynamic pressure, } \mathrm{E} \\
4\end{array}$ \\
\hline$r$ & $=$ & S-duct radial coordinate \\
\hline$R$ & $=$ & $\begin{array}{l}\text { S-duct centerline radius of } \\
\text { curvature }\end{array}$ \\
\hline $\operatorname{Re}_{D_{1}}$ & $=$ & Reynolds number \\
\hline-2 & $=$ & S-duct axial coordinate \\
\hline $\begin{array}{l}x, y, z \\
\theta\end{array}$ & $\begin{array}{l}= \\
=\end{array}$ & $\begin{array}{l}\text { cartesian coordinates } \\
\text { exit plane sector angle }\end{array}$ \\
\hline h & $=$ & S-duct polar angle coordinate \\
\hline
\end{tabular}

Introduction

The common use of diffusing S-ducts in aircraft inlets provides the motivation for exploring their flows. For inlet applications the measure of duct performance is their ability to decelerate the flow to the desired velocity while maintaining high total pressure recovery and flow uniformity at the engine face. Reduced total pressure recovery lowers propulsion efficiency while nonuniform flow conditions at the engine face lower engine surge and stall limits. Improving flow uniformity and total pressure recovery is a matter of great practical interest and is the objective of this research.

The fluid dynamics of the diffusing S-duct used in this study was reported by Vakili $e t$ al. ${ }^{1}$ and Wellbom et $a l^{2}$ Strong cross-stream pressure gradients are developed by the duct's centerline curvature. Within the boundary layer this imparts a transverse or cross-flow velocity. The axial development of this secondary flow into counterrotating vortices at the duct exit plane is responsible for a good deal of flow nonuniformity at the engine face. Throughout this paper, these vortices are referred to as the naturally occurring counter-rotating vortices, since they are present in the flow without any installed vortex generators. Additionally, a streamwise adverse pressure gradient results from increasing cross-sectional area which, for the duct tested here, results in a region of flow separation. This flow separation contributes to the flow blockage that reduces the total pressure recovery of the duct.

Recent work on controlling these detrimental flow features of the diffusing S-duct have considered several approaches. In a follow-up study by Vakili $e$ al. $^{3}$ an array of blade-type vortex generators, set to produce 
counter-rotating axial vortices, was used to prevent separation in the duct. Improvements in the total pressure recovery and total pressure uniformity at the duct exit were reported. The use of a flow control rail device, spanning approximately half of the duct inlet circumference, was not successful in improving the duct performance. In the report of Weng and $\mathrm{Guo}^{4}$ a blade-shaped spoiler divides the inlet cross section of a diffusing rectangular S-duct. At small angles of attack the spoiler reduces the strength of the counter-rotating vortices observed at the duct exit. In a previous study the authors of this report explored the flow control capability of arrays of low profile vortex generators, the so-called "wishbone" types devised by Gary Wheeler. ${ }^{6}$ Systematic variation of the vortex generator size, spacing, and axial location within the duct demonstrated that improvements in total pressure recovery and reduced distortion could be obtained.

The objectives of this study were to reduce distortion and improve total pressure recovery in the diffusing S-duct using tapered-fin type vortex generators. The guiding principle in using these vortex generators was to control the development of secondary flows. This philosophy, as expressed by Anderson et al. ${ }^{7.8}$ differs from the conventional viewpoint of vortex generators as devices that re-energize the boundary layer by mixing free stream and boundary layer fluids. Reported here are results for the bare S-duct and seven different configurations of vortex generators. The configurations vary by the number of vortex generators used and their lateral spacing. The data presented for each configuration include surface static pressure, surface flow visualization, and exit plane total pressure and transverse velocity. The performance of each configuration was assessed by calculating total pressure recovery and inlet distortion descriptors from the data and comparing them to the values for the bare duct. These results should provide valuable guidance in designing vortex generators installations in ducts and for assessing the accuracy of CFD methods to calculate duct flows with installed vortex generators.

\section{Experimental Facilities and Procedures}

\section{Diffusing S-Duct}

The geometry of the diffusing S-duct examined in this study is shown in Fig. 1. This duct is geometrically similar to the duct tested in Ref. 1 and is identical to the duct studied in Refs. 2 and 5 . The duct centerline is defined by two circular arcs with an identical radius of curvature, $R=102.1 \mathrm{cms}$ and subtended angle of $30^{\circ}$. Both arcs lie within the $x z$-plane as shown in Fig. 1. The cross-sectional shape of the duct perpendicular to the centerline is circular. When discussing locations within the duct, axial location will refer to distance to cross-stream planes measured along the duct centerline and normalized by the duct inlet diameter, $s / D_{1}$. Position

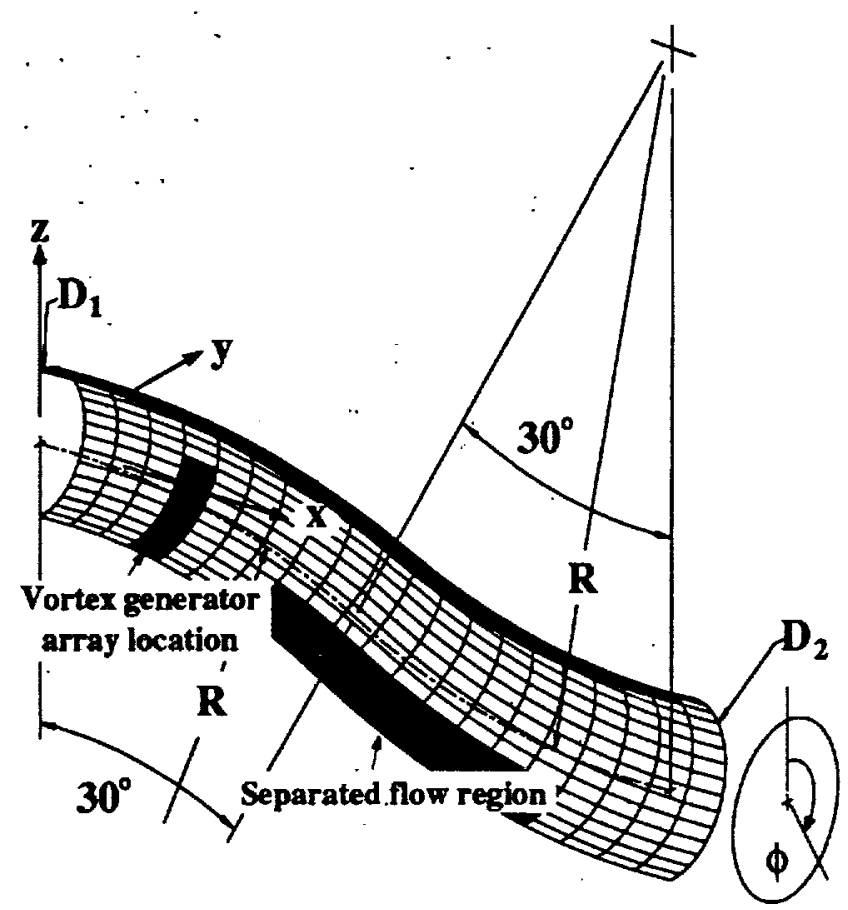

Fig. 1 Geometry of the diffusing S-duct

within cross-stream planes is specified by the polar angle $\phi$, measured from the vertical in a positive clockwise direction as shown in Fig. 1, and the radial distance from the centerline $r$. The diameter of the cross section varies with the axial location and is given by Eq. (1):

$$
\begin{aligned}
\frac{D}{D_{1}}=1 & +3\left(\frac{D_{2}}{D_{1}}-1\right)\left(\frac{s / D_{1}}{5.23}\right)^{2} \\
& -2\left(\frac{D_{2}}{D_{1}}-1\right)\left(\frac{s / D_{1}}{5.23}\right)^{3}
\end{aligned}
$$

In Eq. (1) and Fig. $1 D_{1}=20.4 \mathrm{cms}$ is the diameter at the duct inlet and $D_{2}=25.1 \mathrm{cms}$ is the diameter at the duct exit. This provides an exit to inlet area ratio of $A_{2} / A_{1}=1.52$. The offset of the duct resulting from the centerline curvature is $1.34 D_{1}$, and the length of the duct measured along the centerline is $5.23 D_{1}$.

\section{Facility Flow Conditions}

The tests were conducted at the NASA Lewis Research Center using the Intemal Fluid Mechanics Facility. Air was supplied from the test cell to a large settling chamber containing honeycomb and screens and an axisymmetric contraction having an area ratio of 59:1. Smooth circular pipes of appropriate diameter were attached upstream and downstream of the S-duct to provide a uniform incoming flow and a smooth, continuous condition for flow exiting the duct. The lengths of the upstream and downstream pipes were each $3.75 D_{1}$. After passing through the S-duct the flow was exhausted into a discharge plenum which was continuously evacuated by central exhauster facilities. The duct inlet Mach number was $M=0.6$ for all experimental test conditions 


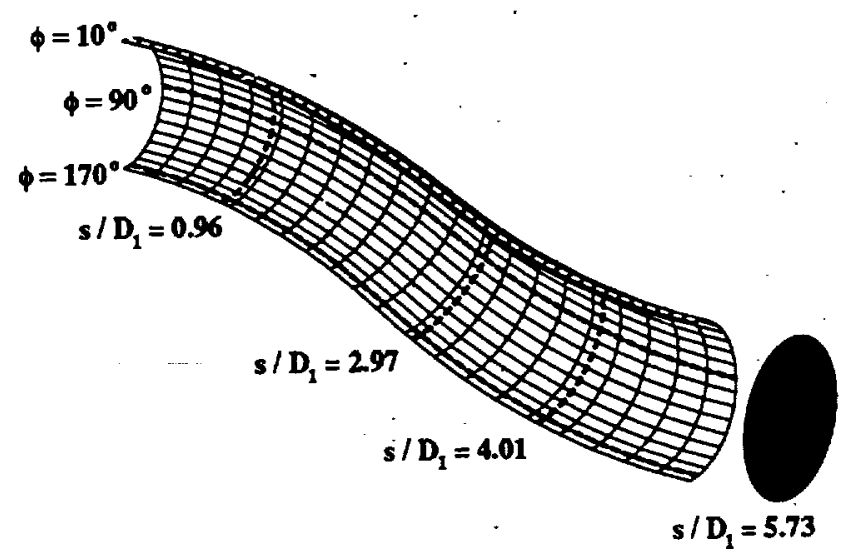

Fig. 2 Location of axial and circumferential static pressure taps and exit measurement plane

and measurements. The inlet boundary layer thickness was approximately $4 \%$ of the duct inlet diameter and the Reynolds number, based on inlet diameter, was approximately $R e_{D_{2}}=2.6 \times 10^{6}$. Test conditions were established by regulating a mass flow valve located between the discharge plenum and the central exhauster facilities. The flow was choked at the mass flow control valve, assuring stable test conditions, unaffected by small pressure variations in the central exhauster equipment. A complete description of the Internal Fluid Mechanics Facility is given by Porro et al. ${ }^{9}$

\section{Measurement Techniques}

The primary set of measurements consist of exit plane surveys of the mean three-dimensional velocity field and total and static pressure. These were acquired by a rake probe consisting of ten equally spaced and independently calibrated five-hole probe tips. The rake probe was traversed circumferentially and radially to acquire data at 720 uniformly spaced grid points in the $(r, \phi)$ exit plane survey grid. Grid resolution on the radial axis was $\Delta r / D_{2}=0.025$ and $\Delta \phi=10^{\circ}$ circumferentially. The exit measurement plane is located at $s / D_{1}=5.73$ and is shown in Fig. 2. More information on the construction, calibration and use of the ten probe rake can be found in the report of Wendt and Reichert. ${ }^{10}$

In addition to the velocity field survey, surface static pressures inside the S-duct were recorded by 220 taps located on axial lines at angles $\phi=10^{\circ}, 90^{\circ}$ and $170^{\circ}$, as well as circumferential lines at $s / D_{1}=0.96,2.97$, and 4.01. The locations of the static pressure taps are indicated by the dashed lines in Fig. 2. Visualization of the near-surface duct flow was achieved by a fluorescent oil dot technique. The flow pattern revealed by the oil dots was both photographed under ultra-violet illumination and transferred to paper by placing paper on the duct surface after the test and allowing the paper to absorb the fluorescent oil.

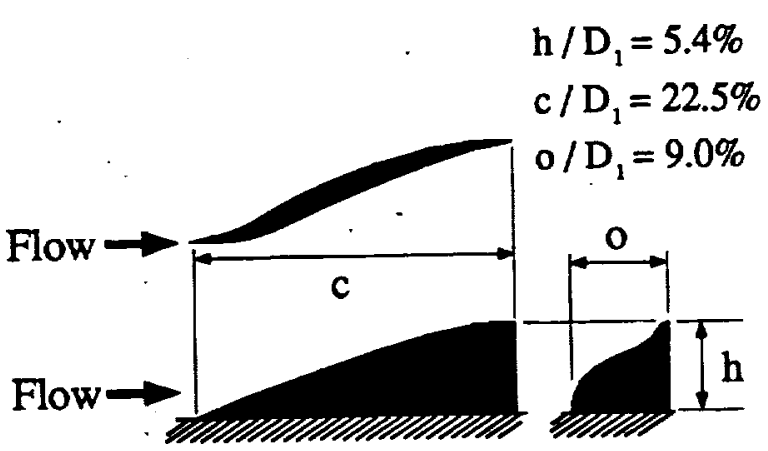

Fig. 3 Tapered fin vortex generator geometry

Vortex Generator Array

The vortex generators used in this study are illustrated in Fig. 3. These devices are similar to the "tapered fin" first examined in the report of Schubauer and Spangenberg. ${ }^{11}$ Each vortex generator will produce a single trailing axial vortex when its leading edge is aligned with the flow as indicated in Fig. 3. The height of the vortex generators tested were on the order the flow field boundary layer thickness.

The basis for suppressing secondary flow using arrays of these devices can be understood from flow visualization data obtained in the diffusing S-duct without vortex generators. Figure 4 illustrates surface flow visualization results, shown as dashed lines, obtained using oil dots. Upstream of the axial location of flow separation $\left(s / D_{1} \approx 2.0\right)$ in the angular range $80^{\circ} \leq \phi \leq 280^{\circ}$ the flow is converging strongly toward the line $\phi=180^{\circ}$. Continuity forces these converging flows away from the duct surface near $\phi=180^{\circ}$. This motion initiates the naturally occurring pair of counter-rotating vortices observed at the duct exit for flow without installed vortex generators. Also, the converging flow of low momentum fluid thickens the boundary layer near $\phi=180^{\circ}$ and reduces its ability to withstand streamwise adverse pressure gradients, contributing to flow separation. The

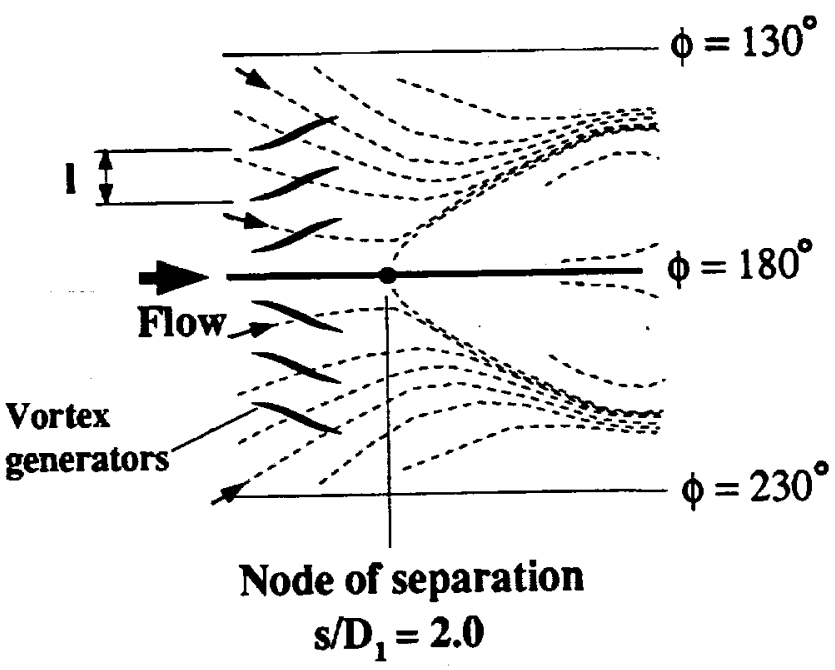

Fig. 4 Array of six vortex generators positioned to counter the duct flow convergence along $\phi=180^{\circ}$ 


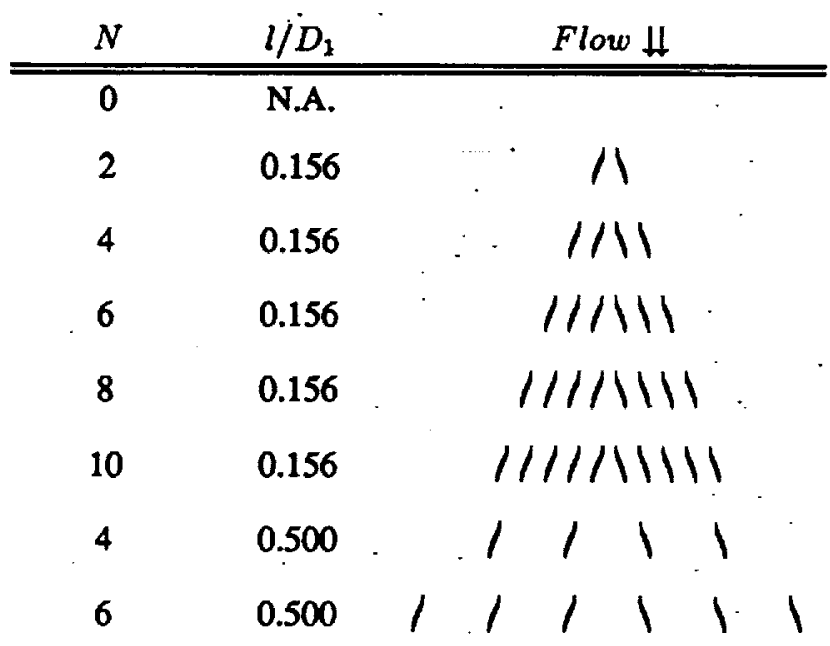

Fig. 5 Vortex generator configurations tested

vortex generators were mounted in arrays to counter this converging flow, as shown in Fig. 4. Six vortex generators are used in the example shown. In a sense, we are using these devices more as boundary layer turning vanes. This viewpoint differs greatly from the conventional interpretation of vortex generator fluid mechanics which attributes their usefulness to a mixing process which reenergizes the boundary layer with free-stream fluid. In this study single cross-stream arrays of vortex generators with this configuration are examined. In each case, the arrays possess mirror image symmetry with respect to the line $\phi=180^{\circ}$ (as in Fig. 4). The axial location of all configurations was at $s / D_{1}=1.6$ and the height of the vortex generators was $h / D_{1}=0.054$, or slightly greater than the inlet boundary layer thickness. The total number of vortex generators used was varied to ascertain its effect on the flow field of the diffusing S-duct. Two lateral spacing ratios, $l / D_{1}=0.156$ and 0.500 , were also studied. Five configurations employed the narrow spacing and two configurations the wide spacing. Table 5 summarizes the vortex generator configurations tested and provides a graphical representation of each configuration.

\section{Results and Discussion}

Static and total pressure plots are presented as pressure coefficients defined by Eqs. 2 and 3 . The pressures $p_{0}$ and $p$ represent the local values of total and static pressure. The reference variables, subscripted ref, were evaluated on the duct centerline at a location one-half duct diameter upstream of the S-duct inlet $\left(s / D_{1}=-0.5\right)$.

$$
\begin{gathered}
C_{p}=\frac{p-p_{\text {ref }}}{p_{0, \text { ref }}-p_{\text {ref }}} \\
C_{p_{0}}=\frac{p_{0}-p_{\text {ref }}}{p_{0, \text { ref }}-p_{\text {ref }}}
\end{gathered}
$$

Figure 6 shows contours of the total pressure coefficient $C p_{0}$ for the bare duct and the seven different arrays of vortex generators tested. The significant distortion in total pressure in Fig. 6a results from the naturally occurring pair of counter-rotating vortices that occur in the duct flow without vortex generators. The mechanism responsible for generating these vortices was described earlier. This is the baseline result that we are attempting to improve by secondary flow control with vortex generators. For the narrow spaced vortex generator configurations, Fig. $6 \mathrm{~b}-\mathrm{f}$, as the number of vortex generators increases the region of low momentum flow is displaced towards either side of the duct in two distinct regions. With eight or more vortex generators the boundary layer is now thinnest along the bottom surface of the duct, at the same location where the naturally-occuring vortices were responsible for the large region of low momentum flow in the absence of vortex generators. This indicates that the secondary flow generated by the vortex generators overcome completely the natural secondary flow. For the wide spaced configurations, Fig. $6 \mathrm{~g}-\mathrm{h}$, it appears that the region of low momentum flow is more evenly distributed along the duct surface when compared to the narrow spaced configurations. This should represent an improvement in total pressure distortion. Also, with vortex generators the overall levels of total pressure appear greater than the bare duct case and seem to reach a maximum for the case of four or six vortex generators (for either narrow or wide spacing), indicating greater total pressure recovery.

Figure 7 shows transverse velocity vectors for the bare duct and the seven different arrays of vortex generators tested. The pair of naturally occurring counterrotating vortices that occur in the flow without vortex generators is apparent in Fig. 7a. For the narrow spaced vortex generator configurations, Fig. $7 \mathrm{~b}-\mathrm{f}$, as the number of vortex generators increase, the strength of the naturally occurring vortices is reduced and they are displaced outwards, away from $\phi=180^{\circ}$. New vortices, resulting from the vortex generators, with rotation opposite of the natural vortices, appear for the cases of four or more vortex generators. The naturally occurring vortices are no longer observed when the number of vortex generators is six or greater. With ten vortex generators, the transverse velocity components are quite large and the entire exit flow field is dominated by two vortices that rotate in a direction opposite to that of the naturally occurring vortices.

The transverse velocity results are much different for the wide spaced configurations, Fig. $7 \mathrm{~g}$-h. For four widely spaced vortex generators, Fig. $7 \mathrm{~g}$, the naturally occuring vortices are barely discernible, whereas for four narrowly spaced vortex generators, Fig. 7c, the naturally occuring vortices are easily identified. In general, the wide spaced vortex generators appear to function more independently then the narrow spaced vortex generators. In Fig. $7 \mathrm{~g}$-h individual vortices from each vortex gener- 


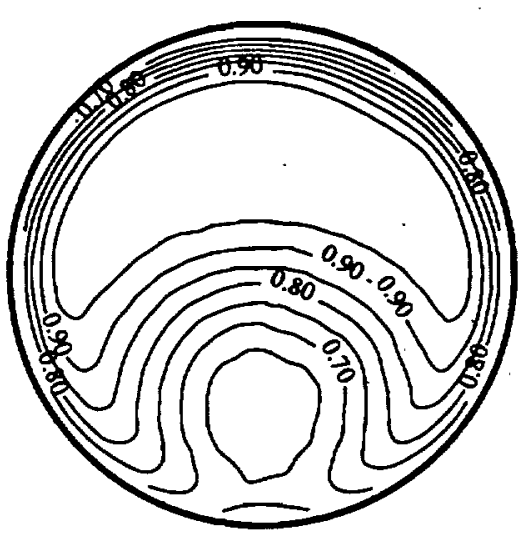

(a) No vortex generators

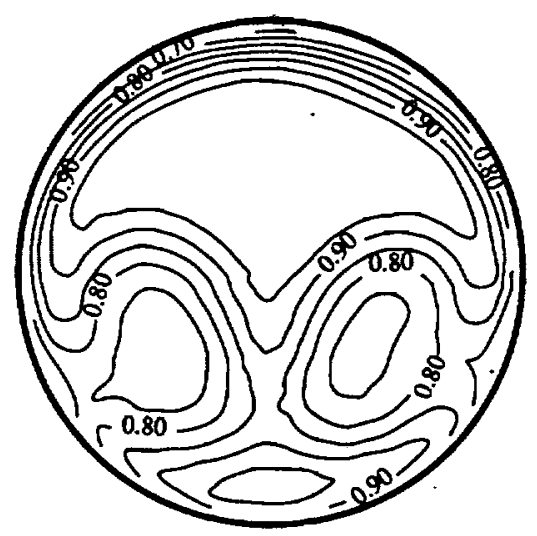

(d) Six vortex generators, narrow spacing

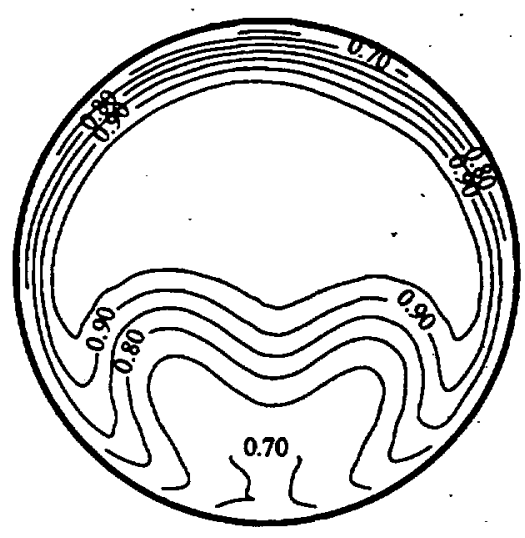

(b) Two vortex generators, narrow spacing

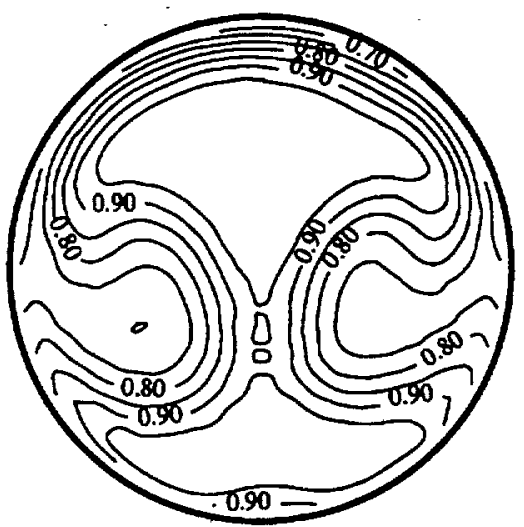

(e) Eight vortex generators, narrow spacing

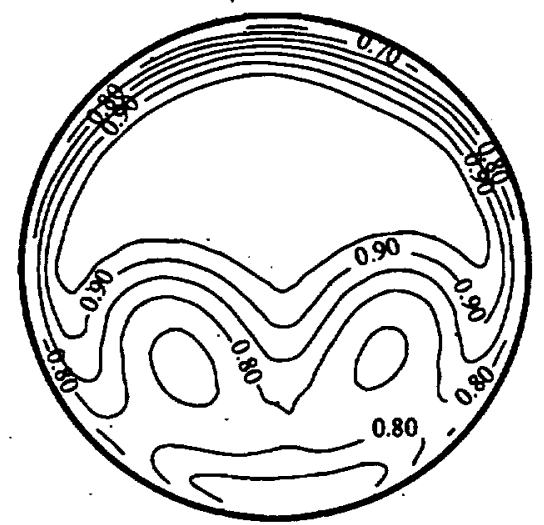

(c) Four vortex generators, narrow spacing

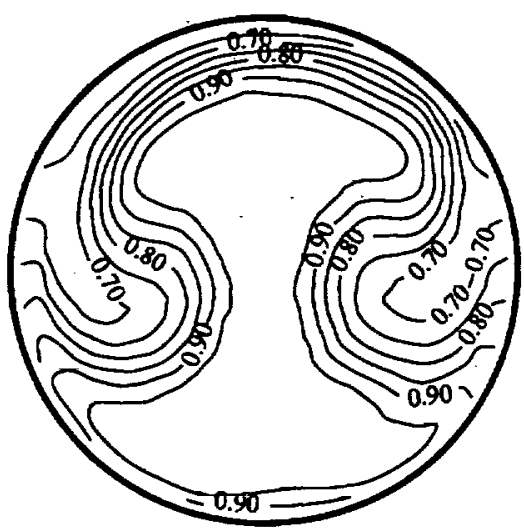

(f) Ten vortex generators, narrow spacing

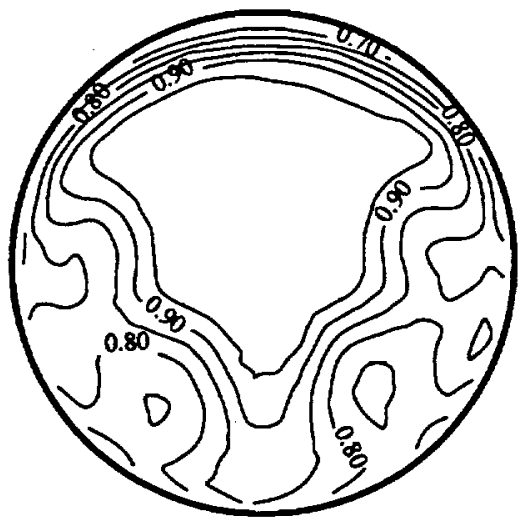

(g) Four vortex generators, wide spacing

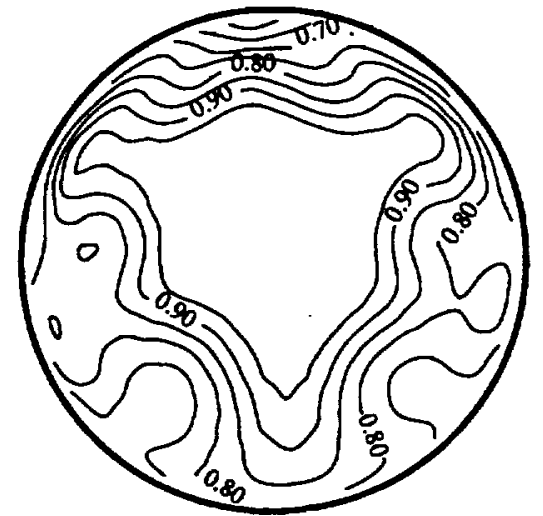

(h) Six vortex generators, wide spacing

Fig. 6 Total pressure contours at $s / D_{1}=5.73$

ator are observed. In contrast, the narrow spaced generators appear to create a single pair of vortices, where the number of vortex generators used determines the strength of the resulting vortex pair.

Figure 8 shows values of axial static pressure and
Fig. 9 circumferential static pressure for the different arrays of vortex generators tested. In both Figs. 8 and 9 the vortex generator results (plotted with solid symbols) are compared with static pressure measurement for flow without vortex generators (plotted with opens symbols). 


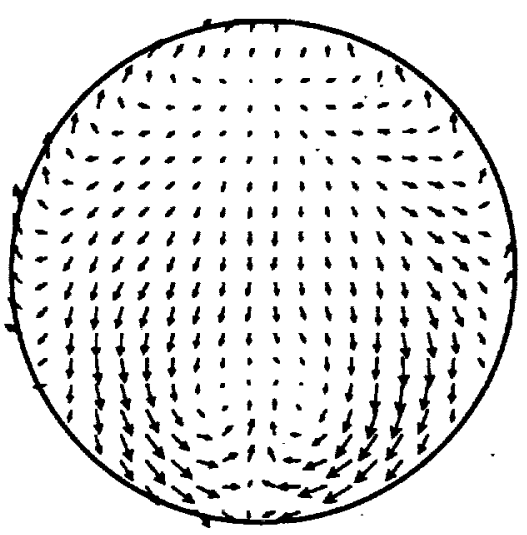

(a) No vortex generators

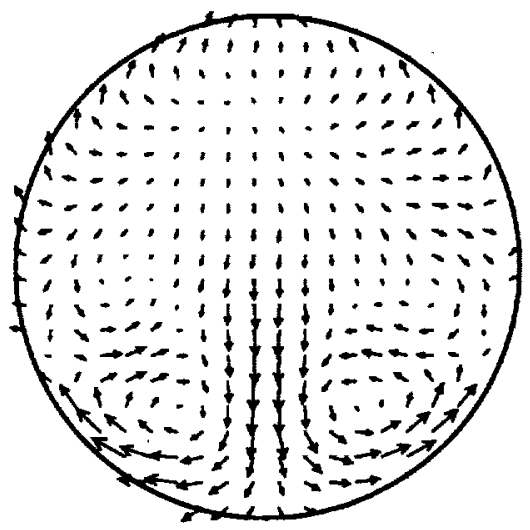

(d) Six vortex generators, narrow spacing

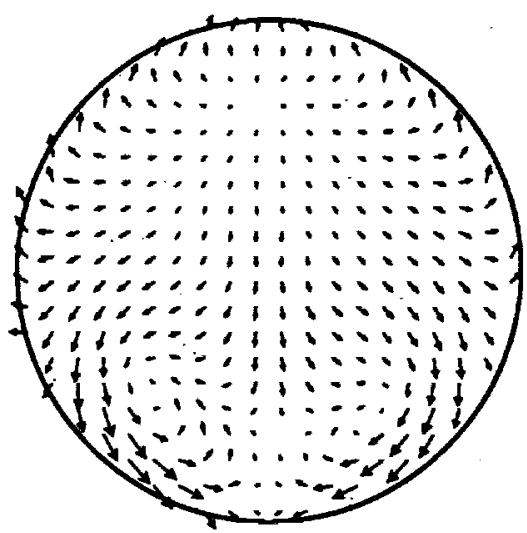

(b) Two vortex generators, narrow spacing

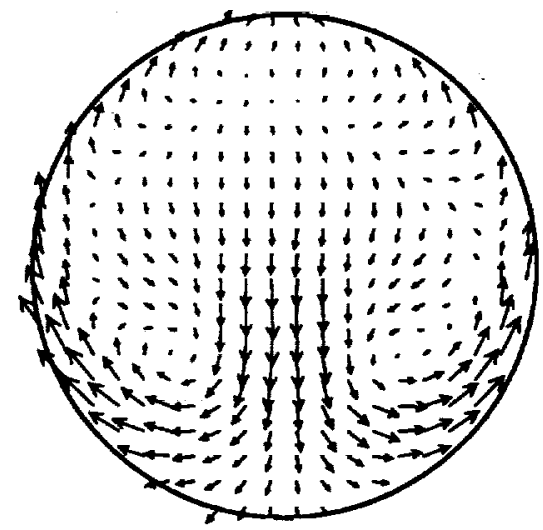

(e) Eight vortex generators, narrow spacing

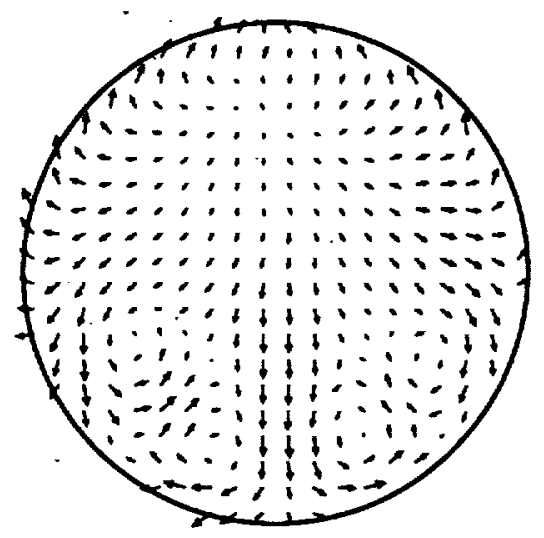

(c) Four vortex generators, narrow spacing

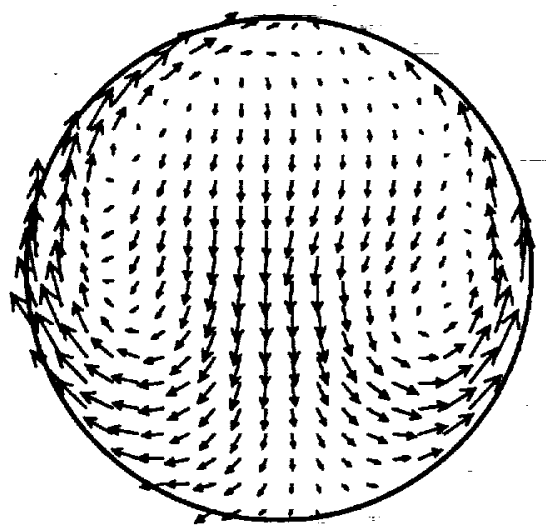

(f) Ten vortex generators, narrow spacing

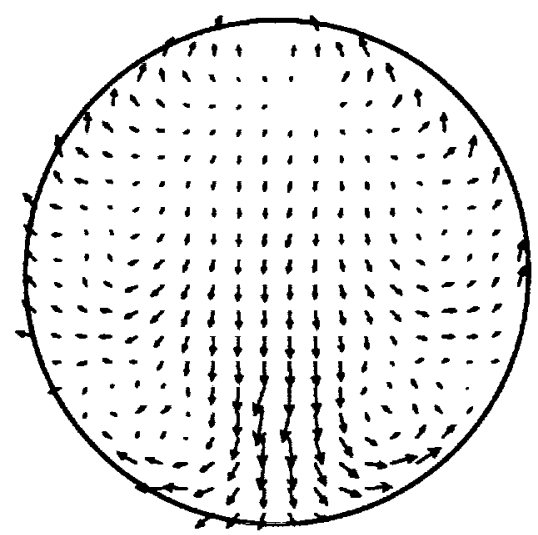

(g) Four vortex generators, wide spacing

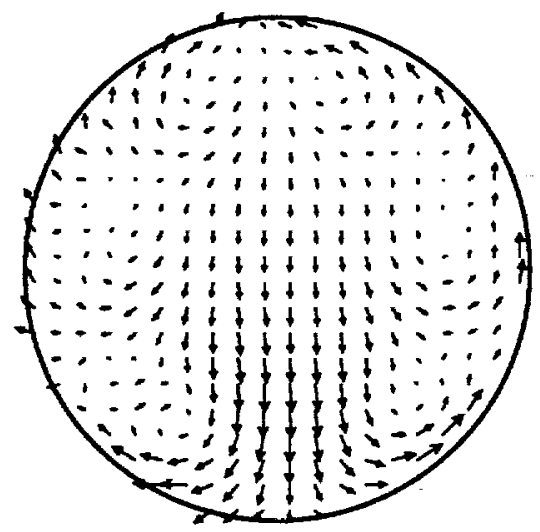

(h) Six vortex generators, wide spacing

Fig. 7 Transverse velocity vectors at $s / D_{1}=5.73$

The dashed vertical line in the axial static pressure plot indicates the axial location of the vortex generator array. The three solid vertical lines in the axial static pressure plot indicates the location of the circumferential static pressure taps, while the three solid vertical lines in the circumferential static pressure plots indicate the location of the axial static pressure taps.

Regarding the static pressure results without vortex generators, the effect of flow separation can be clearly seen. The constant values of axial static pressure at $2<s / D_{1}<3$ for $\phi=90^{\circ}$ and $170^{\circ}$ are associated 


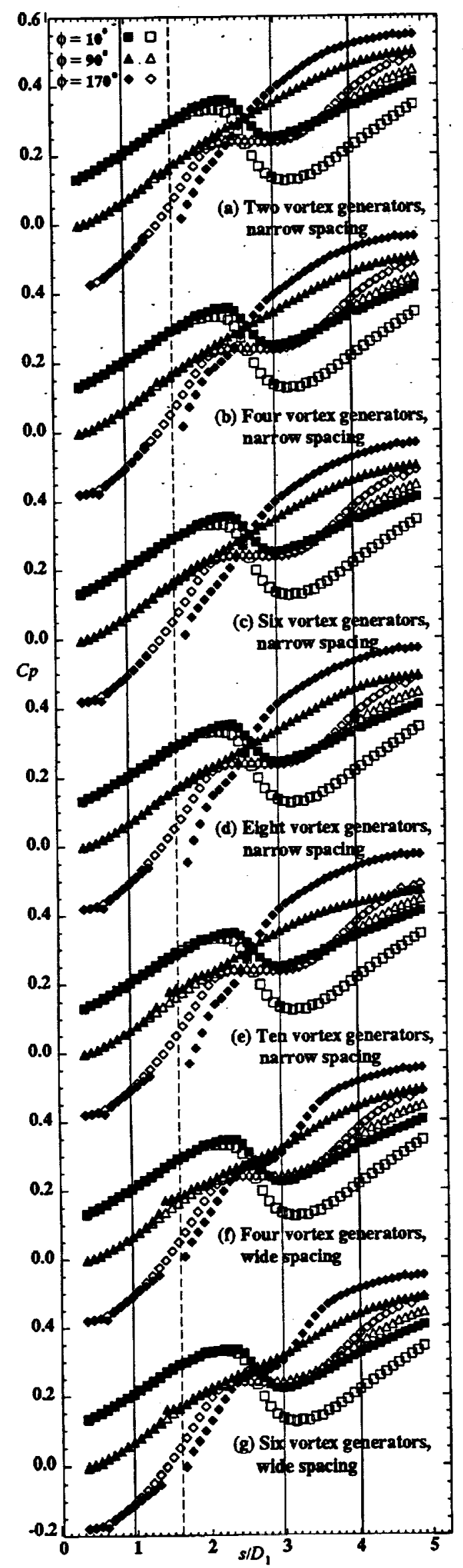

Fig. 8 Axial static pressure

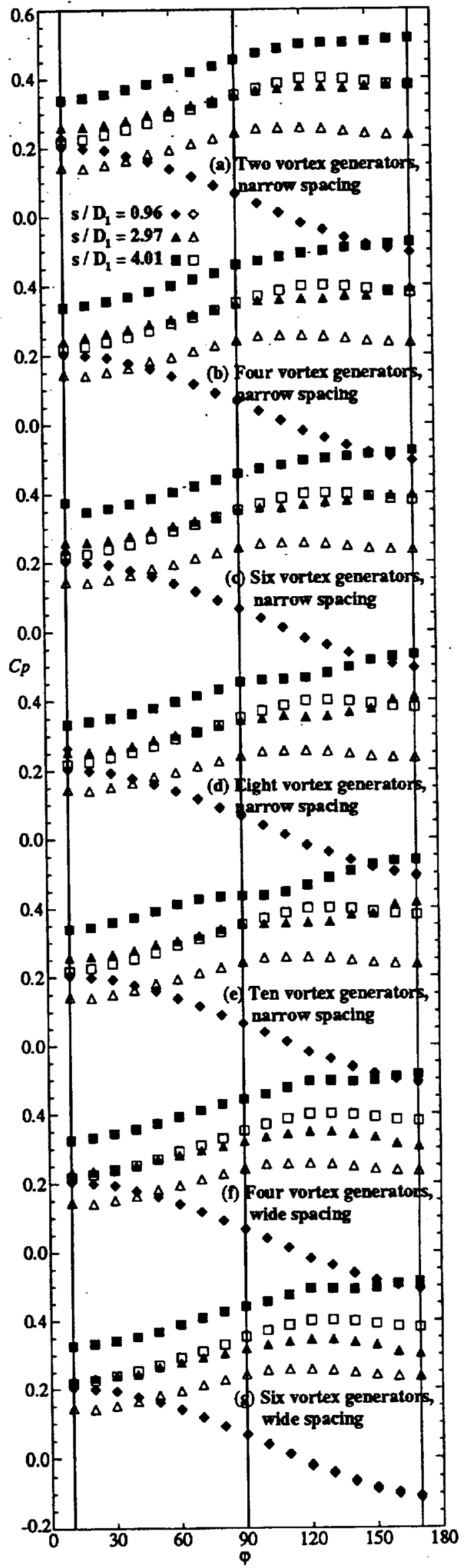

Fig. 9 Circumferential static pressure 


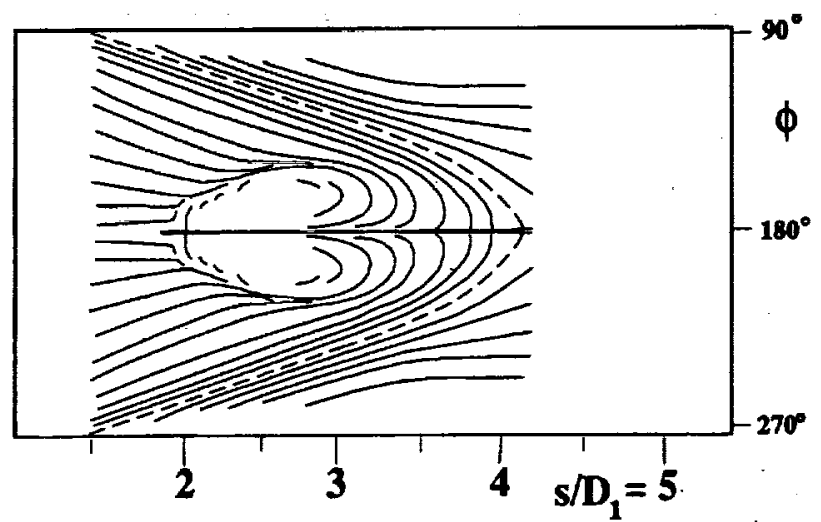

(a) No vortex generators

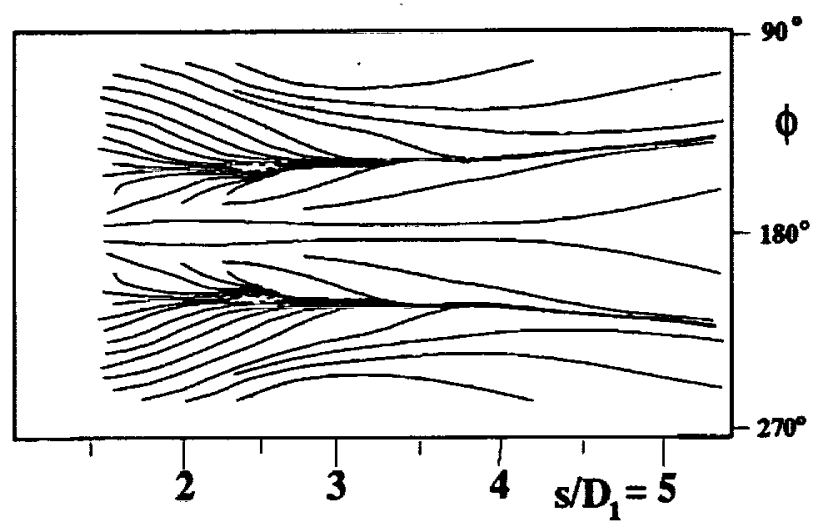

(c) Four vortex generators, narrow spacing

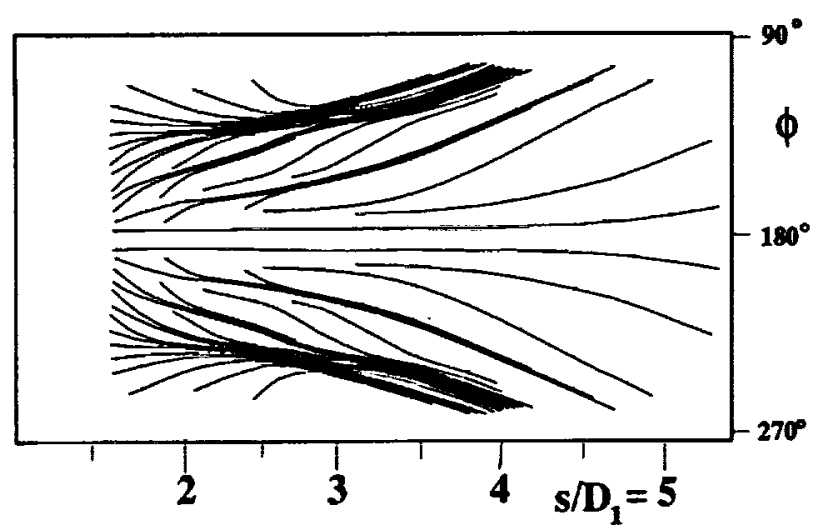

(e) Eight vortex generators, narrow spacing

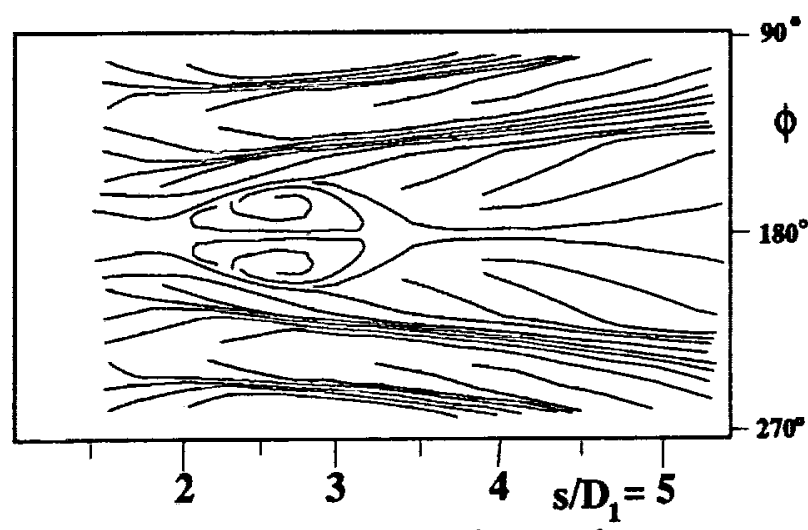

(g) Four vortex generators, wide spacing

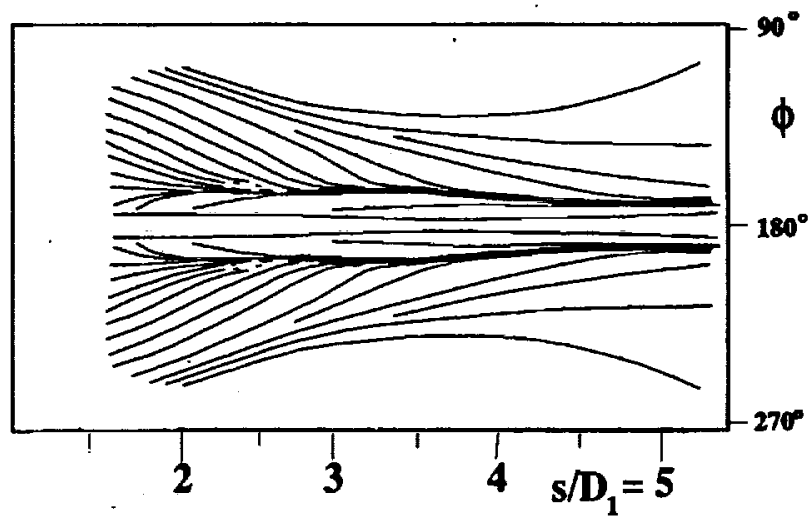

(b) Two vortex generators, narrow spacing

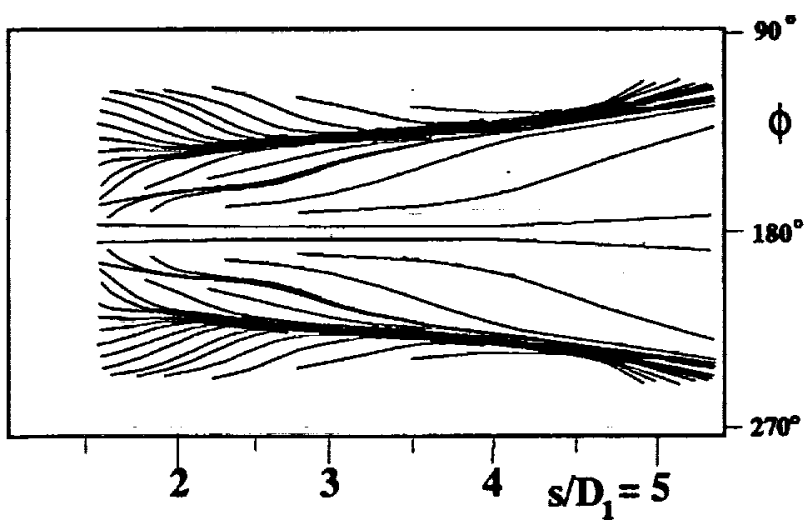

(d) Six vortex generators, narrow spacing

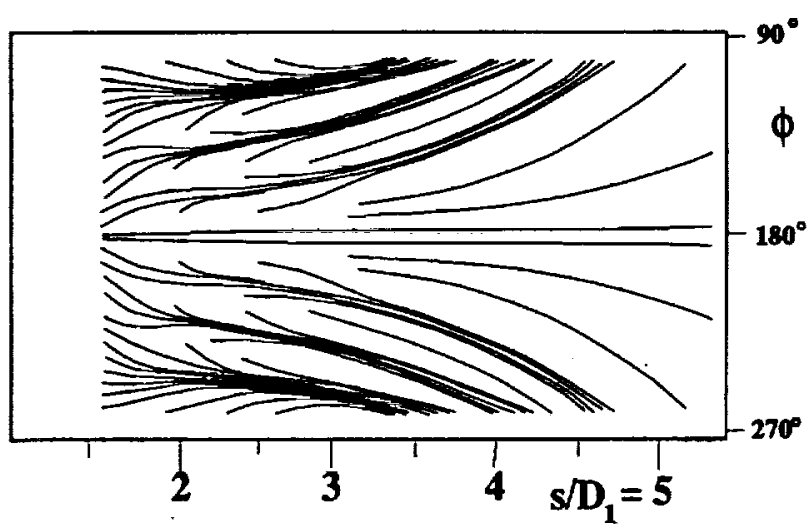

(f) Ten vortex generators, narrow spacing

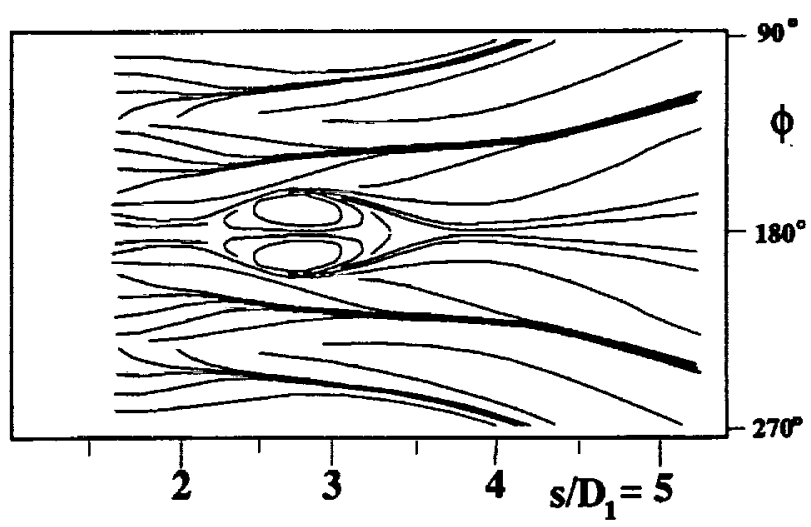

(h) Six vortex generators, wide spacing

Fig. 10 Flow visualization 


\begin{tabular}{|c|c|c|c|c|c|}
\hline Configuration & $\overline{p_{0}} / p_{0 \text { ret }}$ & $\mathrm{DC}(45)$ & $\mathrm{DC}(90)$ & $\mathrm{DC}(135)$ & $\mathrm{DC}(180)$ \\
\hline No vortex generators & $96.55 \%$ & 0.559 & 0.370 & 0.303 & 0.181 \\
\hline $\begin{array}{l}\text { Two vortex generators, } \\
\text { narrow spacing }\end{array}$ & $97.30 \%$ & 0.369 & 0.288 & 0.252 & 0.143 \\
\hline $\begin{array}{l}\text { Four vortex generators, } \\
\text { narrow spacing }\end{array}$ & $97.20 \%$ & 0.278 & 0.171 & 0.203 & 0.132 \\
\hline $\begin{array}{l}\text { Six vortex generators, } \\
\text { narrow spacing }\end{array}$ & $97.14 \%$ & 0.274 & 0.187 & 0.090 & 0.093 \\
\hline $\begin{array}{l}\text { Eight vortex generators, } \\
\text { narrow spacing }\end{array}$ & $96.97 \%$ & 0.299 & 0.177 & 0.069 & 0.023 \\
\hline $\begin{array}{l}\text { Ten vortex generators, } \\
\text { narrow spacing. }\end{array}$ & $96.98 \%$ & 0.376 & 0.187 & 0.112 & 0.080 \\
\hline $\begin{array}{l}\text { Four vortex generators, } \\
\text { wide spacing }\end{array}$ & $97.22 \%$ & 0.236 & 0.168 & 0.100 & 0.100 \\
\hline $\begin{array}{l}\text { Six vortex generators, } \\
\text { wide spacing }\end{array}$ & $96.94 \%$ & 0.229 & 0.132 & 0.079 & 0.072 \\
\hline
\end{tabular}

Table 1 Total pressure recovery and distortion descriptors

with the flow separation. The effect of the separated flow is also evident in the circumferential static pressure at $s / D_{1}=2.97$ and 4.01 , which lie within the region of separated flow. Peak values of static pressure were observed at $\phi=100^{\circ}\left(s / D_{1}=2.97\right)$ and $\phi=120^{\circ}$ $\left(s / D_{1}=4.01\right)$. For unseparated flow the pressure there should increase monotonically for increasing values of $\phi$ with the maximum static pressure at $\phi=180^{\circ}$.

All vortex generator configurations result in higher levels of static pressure. Higher static pressure is a desirable result since the purpose of the diffuser is to decelerate the fiow as efficiently as possible. The highest static pressure at the duct exit was obtained with four narrow spaced vortex generators. The static pressure results suggest that every narrow spaced vortex generator configuration was effective at eliminating flow separation. This conclusion is based on the monotonically increasing levels of axial static pressure for $\phi=90^{\circ}$ and $170^{\circ}$ and the monotonically increasing levels of circumferential static pressure for $s / D_{1}=2.97$ and 4.01. Based on this criterion, the wide spaced vortex generator configurations do not appear to eliminate flow separation. This is most easily seen by comparing Fig. $9 \mathrm{~b}$ and $\mathrm{f}$, particularly the static pressure data at $s / D_{1}=2.97$. In Fig. 9f the peak static pressure occurs at approximately $\phi=130^{\circ}$ and than noticably drops off towards $\phi=180^{\circ}$. In Fig. $9 \mathrm{~b}$ the peak static pressure occurs at $\phi=170^{\circ}$ (static pressure data could not be acquired at $\phi=180^{\circ}$ ).

Figure 10 shows flow visualization results. The drawings were made from the oil visualization patterns that were transferred to paper, as described earlier. In all drawings the flow is from left to right. The separation that is apparent for flow without vortex generators, Fig. 10a, is absent for all narrow spaced vortex generator configurations (although a small region of very low shear stress was evident for the case of two vortex generators). Figure $10 \mathrm{~g}$-h clearly indicates that neither wide spaced vortex generator configuration eliminated flow separation. Comparison with Fig. 10a shows that the extent of separation is reduced. These results confirm similar conclusions drawn earlier from static pressure results.

The strong cross flow that was observed in the transverse velocity vector plots for eight and ten vortex narrow spaced generators is revealed by the rapid divergance of lines from the line $\phi=180^{\circ}$ in the visualization pattern shown in Fig. 10e-f. For two and four narrowly spaced vortex generators the flow diverges slowly, if at all. The visualization results support the idea proposed from transverse velocity vector plots that the wide spaced vortex generators operate more independently than the narrow spaced vortex generators. Because of the wide spacing, the flow pattem developed by the trailing vortices behind the outermost vortex generators in Fig. 10h lies outside the region shown in the drawing.

Table 1 contains the total pressure recovery and distortion descriptors for the bare duct and the seven vortex generator configurations. For these results, the experimental data was evaluated at the probe locations of a standard 40-probe rake. The standard 40-probe rake contains five concentric rings whose radii are located at the centroid of five regions of equal area. Each ring holds eight total pressure probes, spaced at equal $45^{\circ}$ intervals. The mean total pressure, $\overline{p_{0}}$, is then simply the numerical average of the 40 values of total pressure. The distortion descriptor $D C(\theta)$ is defined by Eqn. 4, where $\overline{p_{0}}$ and $\bar{q}$ are mean total and dynamic pressure, averaged over the entire rake and $\overline{p_{0}}(\theta)$ is the mean total pressure in the pie-shaped sector of angular extent $\theta$ that results in the lowest value (hence the greatest value of $D C(\theta)$ ).

$$
D C(\theta)=\frac{\overline{p_{0}}-\overline{p_{0}}(\theta)}{\bar{q}}
$$

From the standpoint of total pressure recovery, the configuration with two narrow spaced vortex generators 
produced the best results, however every vortex generator configuration tested resulted in higher total pressure than the bare duct. There was almost no difference in total pressure recovery between the wide and narrow spaced configurations that employed four vortex generators. This result is particularly interesting since the narrow spaced configuration eliminated separation while the wide spaced configuration did not.

All vortex generator configurations measurably improved total pressure distortion when compared to bare duct results. For $D C(45)$ and $D C(90)$ distortion, the best results for the narrow spaced configuration results were obtained with four or six vortex generators, but for $D C(135)$ and $D C(180)$ distortion, the best narrow spaced configuration results were obtained with eight or ten vortex generators. Comparing wide spacing to narrow spacing for the same number of generators reveals that all distortion measures are improved with wide spacing.

\section{Summary}

This study has shown that vortex generators may be effectively used to control secondary flows that are responsible for the development of naturally occurring counter-rotating vortices observed in diffusing S-ducts flows. These naturally occurring vortices contribute to flow separation and are largely responsible for total pressure distortion at the duct exit. By controlling the secondary flow development, duct performance, as measured by total pressure recovery and distortion, was markedly increased. For this application, the interpretation of the vortex generator fluid mechanics differs significantly from the conventional notion that vortex generators are mixing devices that re-energize the boundary layer with free-stream fluid.

\section{Acknowledgments}

We are grateful for the assistance and insight provided by W. Darby, R. Davis, R. Gronski, W. Hingst, D. Hwang and $T$. Wolfe.

\section{References}

${ }^{1}$ Vakili, A. D., Wu, J. M., Liver, P., and Bhat, M. K., "Experimental Investigation of Secondary Flows in a
Diffusing S-Duct," The University of Tennessee Space Institute Tech. Rep. UTSI 86/14, 1984.

${ }^{2}$ Wellbom, S. R., Reichert, B. A., and Okiishi, T. H., "An Experimental Investigation of the Flow in a Diffusing S-Duct," AIAA Paper 92-3622, 1992. (Also NASA TM 105809).

${ }^{3}$ Vakili, A. D., Wu, J. M., Liver, P., and Bhat, M. K., "Experimental Investigation of Secondary Flows in a Diffusing S-Duct with Vortex Generators," The University of Tennessee Space Institute Preliminary Copy Final Report for NASA Contract NAG3 233, July 1986.

${ }^{4}$ Weng, P. F. and Guo, R. W., "New Method of Swirl Control in a Diffusing S-Duct," AIAA Journal, Vol. 30 , July 1992, pp. 1918-1919.

${ }^{5}$ Reichert, B. A. and Wendt, B. J., "An Experimental Investigation of S-Duct Flow Control Using Arrays of Low Profile Vortex Generators," AIAA Paper 93-0018, 1993. (Also NASA TM 106030).

${ }^{6}$ Wheeler, G. O., "Means for Maintaining Attached Flow of a Flowing Medium," United States Patent 4,455,045, June 1984.

${ }^{7}$ Anderson, B. H. and Levy, R., "A Design Strategy For the Used of Vortex Generators to Manage Inlet- Engine Distortion Using Computational Fluid Dynamics," AIAA Paper 91-2474, 1991. (Also NASA TM 104436).

${ }^{8}$ Anderson, B. H. and Gibb, J., "Application Of Computational Fluid Dynamics To The Study Of Vortex Flow Control For The Management Of Inlet Distortion," AIAA Paper 92-3177, 1992.

${ }^{9}$ Porro, A. R., Hingst, W. R., Wasserbauer, C. A., and Andrews, T. B., "The NASA Lewis Research Center Intemal Fluid Mechanics Facility," NASA TM 105187, Sept. 1991.

${ }^{10}$ Wendt, B. J. and Reichert, B. A., "A New Algorithm for Five-Hole Probe Calibration and Data Reduction and its Application to a Rake-Type Probe," Fluid Measurement and Instrumentation Forum - 1993, edited by R. Gore, T. Morrow, and G. Jones, American Society of Mechanical Engineers, New York, NY, 1993, pp. 29-35.

${ }^{11}$ Schubauer, G. B. and Spangenburg, W. G., "Forced Mixing in Boundary Layers," Journal of Fluid Mechanics, Vol. 8, 1960, pp. 10-31. 
Public reporting bunden for this collection of Information is estimated to average 1 hour per response, including the tme for reviewing instructions, searching existing data sources, gattering and mainlaining the data needed, and complebing and reviewing the collection of lnfomaton. Send comments regarding this burden estimate or any other aspect of his

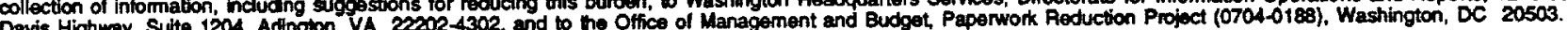

\begin{tabular}{l|l|l|l|} 
3. REPOAT TYPE AND DATES COVERED
\end{tabular}

\begin{tabular}{|l|c|c|}
\hline 1. AGENCY USE ONLY (Leave blank) & $\begin{array}{c}\text { 2. AEPORT DATE } \\
\text { February } 1994\end{array}$ & $\begin{array}{r}\text { 3. REPOAT TYPE AND DATES COVERED } \\
\text { Technical Memorandum }\end{array}$ \\
\hline
\end{tabular}

4. TITLE AND SUBTITLE

Improving Diffusing S-Duct Performance by Secondary Flow Control

6. AUTHOR(S)

Bruce A. Reichert and Bruce J. Wendt
5. FUNDING NUMBERS

WU-505-62-52

8. PERFOAMING ORGANIZATION REPORT NUMBER

E-8479

National Aeronautics and Space Administration

Lewis Research Center

Cleveland, Ohio 44135-3191

10. SPONSORING/MONITOAING AGENCY REPORT NUMBER

National Aeronautics and Space Administration

Washington, D.C. 20546-0001

NASA TM-106492

AIAA-94-0365

11. SUPPLEMENTARY NOTES

Prepared for the 32nd Aerospace Sciences Meeting and Exhibit sponsored by the American Institute of Aeronautics and Astronautics, Reno, Nevada, January 10-13, 1994. Responsible person, Bruce A. Reichert, organization code $2660,(216) 433-8397$.

12a. DISTRIBUTIONAVALABILITY STATEMENT

12b. DISTRIBUTION CODE

Unclassified - Unlimited

Subject Category 02

13. ABSTRACT (Maximum 200 words)

The objective of this research was to study ways to reduce inlet flow distortion (i.e., total pressure nonuniformity) and improve total pressure recovery in a diffusing S-duct. This was accomplished by controlling the development of secondary flows within the duct through the use of tapered-fin type vortex generators. Reported herein are results for the bare duct and seven different configurations of vortex generators. Data presented for each configuration include surface static pressure, surface flow visualization, and exit plane total pressure and transverse velocity. The performance of each configuration was assessed by calculating total pressure recovery and inlet distortion descriptors from the data and comparing them to the values for the bare duct. The best configuration tested reduced distortion (as measured by the $\mathrm{DC}(45)$ and $\mathrm{DC}(90)$ descriptors) by more than $50 \%$ while improving total pressure recovery by $0.5 \%$. These results should provide valuable guidance in designing vortex generator installations in ducts and for assessing the accuracy of CFD methods to calculate duct flows with installed vortex generators.

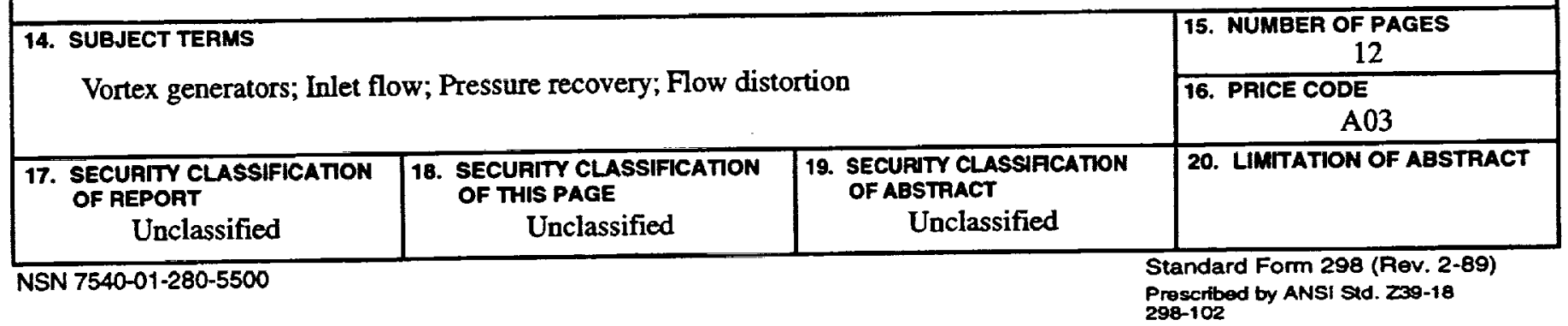

